\title{
SPECTROPHOTOELECTRICAL SENSITIVITY OF PROUSTITE
}

\author{
By W. W. Coblentz
}

ABSTRACT

The present investigation is a continuation of previous work on the spectrophotoelectrical sensitivity of various substances.

At $20^{\circ} \mathrm{C}$ the spectrophotoelectrical sensitivity curve of proustite has a slight maximum at about $0.6 \mathrm{r} \mu$ and a marked sensitivity with a wide maximum (at about $0.3 \mu$ ) in the ultra-violet.

At $-170^{\circ} \mathrm{C}$ the intrinsic spectrophotoelectrical sensitivity is greatly increased; but the maximum reaction is confined mainly in a sharp maximum at $0.578 \mu$. No photoelectrical sensitivity was observed for radiation stimuli of wave lengths extending from $0.7 \mu$ to $2 \mu$.

CONTENTS Page.

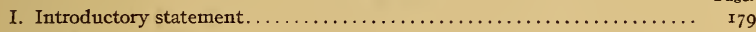

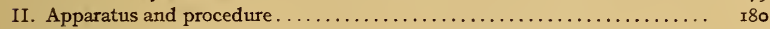

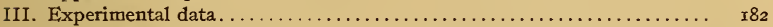

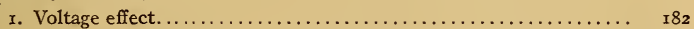

2. Response-time curves. . . . . . . . . . . . . ${ } 8_{2}$

3. Spectrophotoelectrical sensitivity of proustite.............. ${ }_{1} 8_{3}$

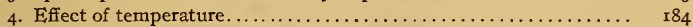

IV. Summary $\ldots \ldots \ldots \ldots \ldots \ldots \ldots \ldots \ldots \ldots \ldots \ldots \ldots \ldots \ldots \ldots \ldots \ldots \ldots \ldots, \quad 185$

\section{INTRODUCTORY STATEMENT}

The present investigation is a continuation of previous work on the spectrophotoelectrical sensitivity of various substances. ${ }^{1}$ As a result of these earlier investigations it has been possible to formulate a few general characteristics of photoelectrical conduction in solids. ${ }^{2}$ It was shown that, in general, the photoelectric response of a substance at room temperatures, when exposed to equal-energy stimuli, is fairly uniform over a wide region of the visible spectrum, terminating in a band or bands of higher sensitivity in the extreme red or near infra-red.

Cuprous oxide ${ }^{3}$ was cited as the only example then known in which the maximum sensitivity is in the ultra-violet, and in which the characteristic band in the red differs from that of the other substances investigated in being almost absent at $20^{\circ} \mathrm{C}$. However, like other substances exhibiting photoelectrical sensitivity,

\footnotetext{
'Molybdenite, B. S. Sci. Papers, 15, p. 121; 1919. Silver sulphide, B. S. Sci. Papers, 15, p. 231; 1919.

${ }^{2}$ B. S. Sci. Papers, 16, p. 635; 1920.

${ }^{3}$ Pfund, Phys. Rev., 7, p. 289; 1916. $38350^{\circ}-21$ 
at low temperatures the reaction of cuprous oxide relative to the rest of the spectrum is confined almost entirely to this band in the red.

In the present paper it will be shown that the spectrophotoelectrical characteristics of proustite, $\mathrm{Ag}_{3} \mathrm{AsS}_{3}$, are similar to those of cuprous oxide. Furthermore, they exhibit similar characteristics in their spectral transmission of thermal radiation. Both are opaque to ultra-violet radiation and begin to transmit freely in the red end of the spectrum, thus imparting to them a bright red or vermilion color.

The one characteristic that all these photoelectrically sensitive substances have in common is a great opacity in the ultra-violet and violet end of the spectrum, followed by a rapid increase in transparency in the red and near infra-red spectrum. This is the long wave-length side of a region of optical resonance with a possible anomalous dispersion. The transmission data at hand on cuprous oxide, proustite, selenium, molybdenite, silver sulphide, etc., show a gradual shifting (or widening) of the absorption band from the ultra-violet into the infra-red. Similarly there is a regular sequence in the decrease in the general spectrophotoelectrical reaction in the short wave lengths and an increase in intensity of the band of high photoelectrical reaction in the red as we go from the spectrically more transparent substances, for example, cuprous oxide and proustite, to the more opaque substances, such as silver sulphide. From this it would appear that the explanation of the photoelectric reaction is to be sought for in an optical resonance phenomenon rather than a change in crystal structure, though the latter of course may contribute to the phenomenon by a change in pleochroism.

Proustite, $\mathrm{Ag}_{3} \mathrm{AsS}_{3}$, is a double sulphide of silver and arsenic. Case ${ }^{4}$ recorded that it is sensitive photoelectrically. One of the reasons for making the examination of this mineral was to obtain a comparison of its spectrophotoelectrical sensitivity with that of silver sulphide. ${ }^{5}$ It is interesting to note that their spectrophotoelectric reactions are entirely different.

\section{APPARATUS AND PROCEDURE}

The arrangement of the apparatus and the methods of operation were practically the same as used in the investigation of molybdenite. ${ }^{6}$ Instead of a fluorite prism, a quartz prism was employed.

'Case, Phys. Rev.. (2) 9, p. 305; 1917.

- B. S. Sci. Papers, 15, p. 120, Fig. 2; 19r9.

${ }^{5}$ B. S. Scl. Papers, 15, p. 23 I; 1919. 
The dispersion of quartz is about twice that of fluorite. The source of radiation was a 500-watt, gas-filled tungsten lamp, mounted in front of the spectrometer slit. Repeated calibrations of the lamp showed that any aging it may have undergone had not affected the equal-energy values used.

The measurements in the ultra-violet were made with a quartzlens spectropyrheliometer ${ }^{7}$ the source of radiation being a CooperHewitt 600-watt quartz-mercury lamp. The emission lines of mercury were reduced to equal-energy stimuli by suitably diaphragming the quartz lens which was used to focus an image of the burner upon the spectrometer slit. In this manner high intensities were obtained which permitted an extension of the photoelectrical measurements into the ultra-violet. (See Fig. r.) High intensities were required in view of the fact that the material examined is not very sensitive and has peculiar electrical properties which prevent the application of a high potential.

The proustite, $\mathrm{Ag}_{3} \mathrm{AsS}_{3}$, used in this investigation came from Chañarcillo, Chile. Two samples were examined. They were of large size, semitransparent, and of a light vermilion color, indicating a high absorptivity for wave lengths less than $0.55 \mu$ $(\mu=0.001 \mathrm{~mm})$.

SAMPLE No. I was a well-formed, homogeneous crystal i 6 by 4 by $3 \mathrm{~mm}$. The terminals were of No. 36 copper wire wound tightly in grooves cut close to the ends of the crystal. The wire and the ends of the crystal were then covered with Woods alloy, which adhered well to the crystal when not applied too hot. The electrodes were attached in this manner with the view of obtaining symmetrical conduction through the crystal. The exposed part of the crystal between the electrodes was $8 \mathrm{~mm}$.

SAMPLE NO. 2 was not so homogeneous in structure, having the appearance of a mass of semitransparent crystals forming a rod I 8 by 6 by $4 \mathrm{~mm}$. The electrodes were applied to sample No. 2 in the same manner as to sample No. I, just described. The exposed part of the crystal between the electrodes was ro $\mathrm{mm}$.

The electrodes of both crystals were covered with cardboard to prevent exposure to radiation. For making the observations at low temperatures the samples were mounted in the evacuated glass container described in previous papers. When making the measurements at $22^{\circ} \mathrm{C}$ the sample was mounted at the exit slit of the spectrometer. The intensity of the radiation stimulus was 
therefore three to four times larger than usually employed, and it was possible to investigate the visible spectrum more accurately.

The photoelectrical changes in conductivity were determined by connecting the crystal of proustite in series with a high resistance ( 10000 to $30000 \mathrm{ohms}$ ), a potential of $\mathrm{I.4}$ to 4 volts, and a d'Arsonval galvanometer.

Proustite is classed as a good conductor and hence a special arrangement of batteries and shunts ${ }^{8}$ would be required in order to apply high voltages.

\section{EXPERIMENTAL DATA}

Considerable difficulty was experienced in making observations on these crystals, owing to the unsteadiness of the zero reading. This is probably attributable to the large mass of material under examination. At least that was the explanation arrived at in an examination ${ }^{9}$ of stibnite where thin samples were also obtainable.

In the preliminary examination of different parts of the crystal it was found that, unlike molybdenite, these two samples of proustite were fairly uniform in sensitivity.

No "positive-negative" effect, such as was found in a certain sample of molybdenite, ${ }^{10}$ could be observed in proustite.

\section{VOLTAGE EFFECT}

The increase in conductivity with increase in the applied voltage, which has been described by previous experimenters, was especially marked in proustite. Moreover, on applying a constant voltage the conductivity increased greatly with time. This was overcome to some extent by applying a high potential for a while, then reducing it to 1.4 volts (a single dry battery). Even then it was necessary to wait an hour or more before making observations.

\section{RESPONSE-TIME CURVES}

For proustite, the curve illustrating the progress of the photoelectric reaction with time was found quite similar to that of other substances (for example, molybdenite) described in previous papers. When the reaction was small, the maximum deflection was observed in 5 to ro seconds and the time for recovery was not greatly prolonged. On the other hand, when observing in the region of the maximum photoelectric action (at $0.578 \mu$ ) at low temperatures the time to attain a maximum reaction was prolonged 
to 45 seconds or longer, and the time necessary for recovery was two to three times the time of exposure.

\section{SPECTROPHOTOELECTRICAL SENSITIVITY OF PROUSTITE}

The spectrophotoelectric reaction of proustite at $22^{\circ} \mathrm{C}$. is illustrated in Fig. $\mathrm{I}$, the samples being exposed at the exit slit of the spectrometer, as already explained. In this illustration the observations on sample No. I are indicated by the continuous curves and those on sample No. 2 by the dotted curves.

The two curves to the right, marked $B$, depict the results of a careful examination of the small maximum in the region of $0.6 \mathrm{I} \mu$ It will be shown presently that, with decrease in temperature, this maximum very rapidly overtakes and exceeds the reaction in the rest of the spectrum and shifts to shorter wave lengths as observed in previous work on other substances.

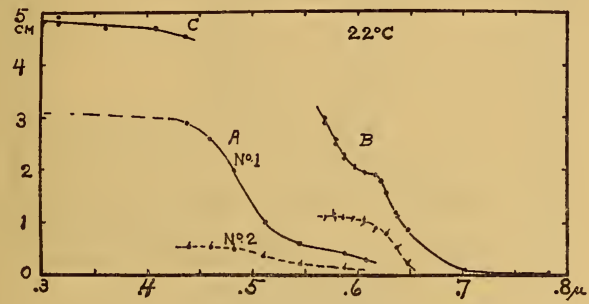

FIG. I. - Spectrophotoelectrical sensitivity of proustite. (Ordinates are galvanometer deflections)

In the two curves marked $A$, which are to the left in the illustration, the observations are extended into the violet. For this purpose the tungsten lamp had to be operated on a lower current in the region of $0.6 \mu$. The radiation intensities are $B=7 A$. For sample No. I curve $A$ is extended by a dashed line to illustrate what is to be expected in the ultra-violet.

The observations on sample No. $I$ in the ultra-violet are illustrated in curve $C$, Fig. I. They were obtained by using a quartzmercury vapor lamp and a quartz spectropyrheliometer, as already described.

The results of this examination show that, at $22^{\circ} \mathrm{C}$, the spectrophotoelectrical sensitivity curve of proustite consists of a wide band, with a maximum in the ultraviolet, and a small, ill-defined maximum in the orange-yellow of the spectrum. In this respect 
the spectrophotoelectric response curve is similar to that of cuprous oxide.

No photoelectric reaction could be observed for radiations extending to $2 \mu$.

\section{EFFECT OF TEMPERATURE}

In order to make this test the sample was mounted in an evacuated glass container which was immersed in liquid air as already described..$^{11}$

The effect of temperature upon the spectrophotoelectric reaction of proustite is illustrated in Figs. 2 and 3 . The former gives the photoelectric reaction of samples No. I and No. 2 (curves $I$ and 2, Fig. 2) at $-125^{\circ} \mathrm{C}$ and $-126^{\circ} \mathrm{C}$, respectively. They are interesting in showing that, although the intrinsic sensitivity of sample

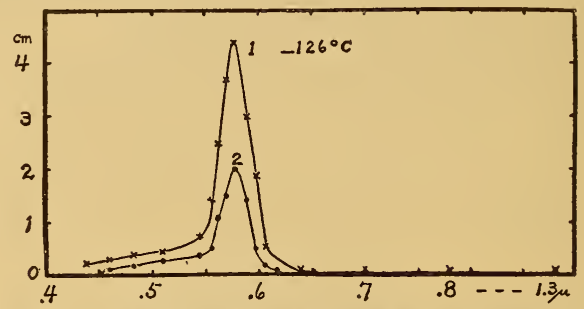

Frg. 2.-Effect of temperature upon the spectrophotoelectrical sensitivity of proustite

No. 2 is much less than that of No. I, their spectrophotoelectric reactions are similar, both showing a marked development of the band at $0.578 \mu$.

In Fig. 3 is depicted the rapid growth of the band at $0.578 \mu$. From $+22^{\circ} \mathrm{C}$ to $-49^{\circ} \mathrm{C}$ this band is imperceptible. At $-93^{\circ} \mathrm{C}$ the wide maximum in the violet is still observable, while the one at $0.578 \mu$ has become sharp and well defined. From - IoI $^{\circ} \mathrm{C}$ to $-125^{\circ} \mathrm{C}$ the band at $0.578 \mu$ greatly exceeds the violet band. From these curves it appears that the band at $0.578 \mu$ does not suddenly envelop the ultra-violet band at a definite temperature, but that between $-50^{\circ} \mathrm{C}$ and $-90^{\circ} \mathrm{C}$ there is a gradual interchange in the relative intensities of the two maxima.

While observing these three curves the applied potential (I.4 volts) remained constant. Consequently, as the temperature de-

11 B. S. Sci. Papers, 15, p. 120, Fig. 2; 1919. 
creased the resistance increased, and, although the intrinsic spectrophotoelectrical sensitivity was greatly increased, the galvanom. eter deflections remained of the same order of magnitude. Hence, for the purpose of clearly depicting the isothermal spectrophotoelectric reactions in this illustration (Fig. 3), the ordinates of the $-49^{\circ} \mathrm{C}$ curve are two times that of the $22^{\circ} \mathrm{C}$ curve; also the ordinates of the $-93^{\circ} \mathrm{C}$ curve and of the - ror $^{\circ} \mathrm{C}$ curve are five times that of the $22^{\circ} \mathrm{C}$ curve.

Furthermore, in order to avoid confusion in Fig. 3, the zero of the ordinates of the isothermal spectrophotoelectric reaction curves observed at $-125^{\circ} \mathrm{C}$ and at $-167^{\circ} \mathrm{C}$ is raised. In these

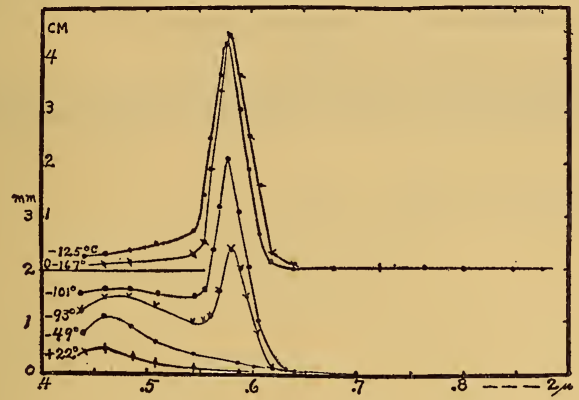

Fig. 3.-Spectrophotoelectrical sensitivity curves of proustite at various temperatures

two curves the galvanometer deflections were much larger than those observed at the higher temperatures. However, owing to the long time required for the reaction to attain equilibrium, as already explained, the observations at $0.578 \mu$ were subject to some uncertainty. The conclusion to be drawn for these curves is that the sharp maximum at $0.578 \mu$ remains fairly constant in position with decrease in temperature

\section{SUMMARY}

In the foregoing pages experimental data are given on the spectrophotoelectrical sensitivity of the mineral proustite, which is a double sulphide of silver and arsenic. The results obtained show that the photoelectric reaction is entirely different from that of silver sulphide. 
The samples were exposed to thermal radiation stimuli extending from $0.3 \mu$ to $2 \mu$. The greatest photoelectrical activity occurs in the region of the spectrum $(0.5 \mu$ to $0.7 \mu)$ where there is a rapid decrease in spectral absorption. No photoelectric reaction was observed for wave lengths greater than $0.7 \mu$.

It was found that at $22^{\circ} \mathrm{C}$ the photoelectric reaction of proustite consists of a wide maximum in the ultra-violet, with a weak, illdefined maximum in the region of $0.61 \mu$.

On lowering the temperature to $-167^{\circ} \mathrm{C}$ the intrinsic sensitivity is greatly increased throughout the spectrum. The illdefined maximum at $0.61 \mu$ increases greatly in intensity and shifts to $0.578 \mu$.

At low temperatures the greatest spectrophotoelectric reaction is localized in the band at $0.578 \mu$.

All the data are in agreement with the previously formulated general characteristics of spectrophotoelectrical sensitivity in solids.

WASHINGTON, January 7, $192 \mathrm{r}$. 